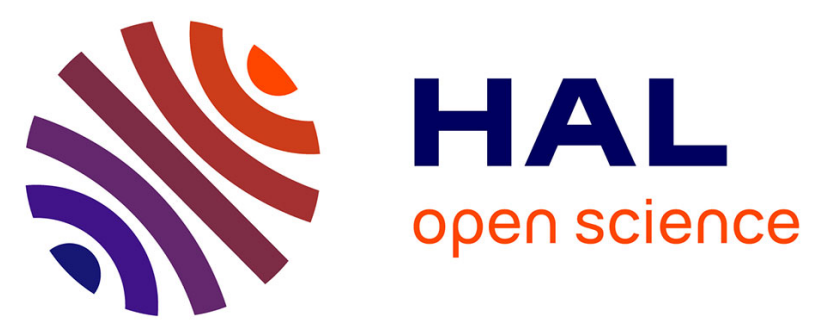

\title{
T-cell defect in Diffuse Large B-cell Lymphomas involves expansion of myeloid derived suppressor cells expressing IL-10, PD-L1 and S100A12
}

\author{
Imane Azzaoui, Fabrice Uhel, Delphine Rossille, Celine Pangault, Joelle \\ Dulong, Jerome Le Priol, Thierry Lamy, Roch Houot, Steven Le Gouill, \\ Guillaume Cartron, et al.
}

\section{To cite this version:}

Imane Azzaoui, Fabrice Uhel, Delphine Rossille, Celine Pangault, Joelle Dulong, et al.. T-cell defect in Diffuse Large B-cell Lymphomas involves expansion of myeloid derived suppressor cells expressing IL-10, PD-L1 and S100A12. Blood, 2016, 128 (8), pp.1081-1092. 10.1182/blood-2015-08-662783 . hal-01394657

\section{HAL Id: hal-01394657 \\ https://hal-univ-rennes1.archives-ouvertes.fr/hal-01394657}

Submitted on 9 Nov 2016

HAL is a multi-disciplinary open access archive for the deposit and dissemination of scientific research documents, whether they are published or not. The documents may come from teaching and research institutions in France or abroad, or from public or private research centers.
L'archive ouverte pluridisciplinaire HAL, est destinée au dépôt et à la diffusion de documents scientifiques de niveau recherche, publiés ou non, émanant des établissements d'enseignement et de recherche français ou étrangers, des laboratoires publics ou privés. 


\section{T-cell defect in Diffuse Large B-cell Lymphomas involves expansion of myeloid derived suppressor cells expressing IL-10, PD-L1 and S100A12}

Imane Azzaoui ${ }^{1}{ }_{\text {Fabrice Uhel, }}^{2,3,4,5}$ Delphine Rossille, ${ }^{1,3,4,5}$ Celine Pangault, ${ }^{1,3,4,5}$ Joelle Dulong, ${ }^{1,3,4,5}$ Jerome Le Priol, ${ }^{1}$ Thierry Lamy, ${ }^{3,4,5,6}$ Roch Houot, ${ }^{3,4,5,6}$ Steven Le Gouill, ${ }^{7}$ Guillaume Cartron, ${ }^{8}$ Pascal Godmer, ${ }^{9}$ Krimo Bouabdallah, ${ }^{10}$ Noel Milpied, ${ }^{10}$ Gandhi Damaj, ${ }^{11}$ Karin Tarte, ${ }^{1,3,4,5}$ Thierry Fest ${ }^{1,3,4,5}$ and Mikael Roussel ${ }^{1,3,4,5}$

${ }^{1} \mathrm{CHU}$ de Rennes, Pôle Biologie, Rennes, France

${ }^{2} \mathrm{CHU}$ de Rennes, Maladies Infectieuses et Réanimation Médicale, Rennes, France

${ }^{3}$ INSERM, UMR U917, Equipe Labellisée Ligue Contre le Cancer, Rennes, France

${ }^{4}$ Université Rennes 1, UMR917, Rennes, France

${ }^{5}$ EFS Bretagne, Rennes, France

${ }^{6} \mathrm{CHU}$ de Rennes, Service d'Hématologie Clinique, Rennes, France

${ }^{7} \mathrm{CHU}$ de Nantes, Service d'Hématologie Clinique, UMR 892 équipe 10, Nantes, France

${ }^{8} \mathrm{CHU}$ de Montpellier, Service d'Hématologie Clinique, Montpellier, France

${ }^{9} \mathrm{CH}$ de Bretagne Atlantique, Unité d'Hématologie Clinique, Vannes, France

${ }^{10} \mathrm{CHU}$ de Bordeaux, Service d'Hématologie Clinique, Bordeaux, France

${ }^{11} \mathrm{CHU}$ de Caen, Service d'Hématologie Clinique, Bordeaux, France

Short title: M-MDSCs in DLBCL

\section{Corresponding author:}

Karin Tarte, INSERM U917, Faculté de Médecine, 2 Avenue du Pr Léon Bernard, F35043 Rennes France, E-mail: karin.tarte@univ-rennes1.fr, Phone: +33 (0) 223234 512, fax: +33 (0) 223234 958; or Thierry Fest, INSERM U917, Faculté de Médecine, 2 Avenue du $\operatorname{Pr}$ Léon Bernard, 35043 Rennes Cedex, France, E-mail: thierry.fest@univ-rennes1.fr, Phone: +33 (0) 299284 127, Fax: +33 (0) 299284 152; or Mikael Roussel, Laboratoire Hématologie, CHU Pontchaillou, 2 rue Henri Le Guilloux, 35033 Rennes Cedex, France, E-mail: mikael.roussel@chu-rennes.fr 


\title{
Key points
}

- Expansion of circulating monocytic myeloid derived suppressor cells (MDSCs) correlates with clinical outcomes in patients with DLBCL.

- Mechanisms of MDSC-dependent T-cell inhibition in DLBCL are related to IL-10, PD-L1 and S100A12.

\begin{abstract}
In diffuse large B-cell lymphoma (DLBCL), the number of circulating monocytes and neutrophils represents an independent prognostic factor. These cell subsets include monocytic and granulocytic myeloid derived suppressor cells (M- and G-MDSCs) defined by their ability to suppress T-cell responses. MDSCs are a heterogeneous population described in inflammatory and infectious diseases as well as in numerous tumors including multiple myeloma, chronic lymphocytic leukemia and DLBCL. However, their mechanisms of action remain unclear. We broadly assessed the presence and mechanisms of suppression of MDSC subsets in DLBCL. First, a myeloid suppressive signature was identified by gene expression profiling in DLBCL peripheral blood. Accordingly, we identified in a cohort of 66 DLBCL patients an increase in circulating G-MDSC ( $\left(\operatorname{Lin}^{\text {neg }} \mathrm{HLA}-\mathrm{DR}^{\text {neg }} \mathrm{CD} 33^{\text {pos }} \mathrm{CD} 11 \mathrm{~b}^{\text {pos }}\right.$ ) and M-MDSC (CD14 $\left.{ }^{\text {pos }} \mathrm{HLA}-\mathrm{DR}^{\text {low }}\right)$ counts. Interestingly, only M-MDSC number was correlated with the International Prognostic Index (IPI), the event-free survival (EFS), and the number of circulating $\mathrm{T}_{\text {reg. }}$. Furthermore, T-cell proliferation was restored after monocyte depletion. Myeloid-dependent T-cell suppression was attributed to a release of IL-10 and S100A12 and an increased PD-L1 expression. In summary, we identified expanded MDSC subsets in DLBCL as well as new mechanisms of
\end{abstract}




\section{Introduction}

Diffuse large B-cell lymphoma (DLBCL) is the most common non-Hodgkin lymphoma, accounting for around $40 \%$ of new cases. Although DLBCL is recognized as a single entity by the World Health Organization, several subgroups with different outcomes have been described. ${ }^{1}$ Despite introduction of immunotherapy, treatment failure is observed in around $40 \%$ of DLBCL, emphasizing the need for prognostic biomarkers. $^{2}$ The International Prognostic Index (IPI), with variants, still considered the standard prognostic factor for DLBCL, stratifies patients at diagnosis. However this score does not take into account biological differences among subgroups. ${ }^{3-5}$ Additional prognostic factors, evaluated at the time of diagnosis, include various cytokines (soluble PD-L1 $\left.{ }^{6} \mathrm{CxCL} 10,{ }^{7} \mathrm{IL}-10\right)^{7}$, tumor characteristics (cell of origin, ${ }^{8}$ LMO2, ${ }^{9}$ MYC-, BCL2- and BCL6-rearrangements) ${ }^{10}$ and components from the tumor microenvironment $\left(\mathrm{CD} 3^{\text {pos }}, \mathrm{CD} 4^{\text {pos }}\right.$ and Foxp3 tumor infiltrating $\mathrm{T}$ cells, ${ }^{11,12} \mathrm{CD} 68^{\text {pos }}$ myeloid cells). ${ }^{2,13,14}$ Recently, an increase in circulating neutrophil ${ }^{15}$ or monocyte ${ }^{16,17}$ counts, combined with a decrease in lymphocyte count (so-called LMR: lymphocyte to monocyte ratio and NLR: neutrophil to lymphocyte ratio) have been proposed as independent prognostic markers in the Rituximab era.

Specific granulocyte and monocyte subsets have demonstrated their immunosuppressive functions in cancers as well as in inflammatory diseases and are recognized as myeloid derived suppressor cells (MDSCs). ${ }^{18,19}$ These cells are immature, arise from the myeloid lineage, and are defined by their immunosuppressive function. Human MDSCs, a heterogeneous population with a lack of specific markers, belong to 2 major types: granulocytic (G-MDSC, Lin ${ }^{\text {neg } H L A-~}$ 
have been associated with MDSCs. ${ }^{19}$ Interestingly, these markers are likely regulated through various stimuli depending on the tumor type. ${ }^{20}$ MDSC induction and expansion are mediated by a combination of soluble factors (including VEGF, GMCSF, M-CSF, S100A8/A9, IL-4, IL-6, IL-10) produced by tumor and/or surrounding cells such as stromal cells, T cells or macrophages. ${ }^{19}$ These factors essentially trigger activation of the STAT3, STAT6 and STAT1 family, leading to the expression of genes involved in the blockade of the myeloid differentiation or in immune regulation. These multiple suppressive mechanisms converge to impair effector $\mathrm{T}$ cell and NK cell functions and also contribute to macrophage polarization towards a M2 anti-inflammatory phenotype. In human, various mechanisms have been described including $i$ ) regulatory $\mathrm{T}$ cell $\left(\mathrm{T}_{\mathrm{reg}}\right)$ expansion, ii) depletion in amino acids essential for T-cell metabolism by expression of arginase 1 (ARG1) or indoleamine 2,3dioxygenase (IDO), iii) production of reactive oxygen species (ROS) by expression of NADPH oxidase (NOX2), and iv) IL-10, TGF $\beta$ release and PD-L1 expression. ${ }^{20,21}$

In most solid cancers studied (melanoma, renal, lung or prostate cancer, hepatocellular carcinoma), although both G- and M-MDSCs were increased, a predominance of G-MDSCs was mostly detected. ${ }^{22,23}$ However, by using a model which allowed separate study of G- and M-MDSCs in tumor-bearing mice, Haverkamp et al. demonstrated that M-MDSC was the most suppressive subset and that loss of G-MDSCs did not alter tumor incidence. ${ }^{24}$ In lymphoid malignancies, an enrichment in circulating MDSCs has been described in myeloma, ${ }^{25}$ T-cell lymphoma, ${ }^{26}$ chronic lymphocytic leukemia $(C L L)^{27}$ and DLBCL. ${ }^{28,29}$ In DLBCL, GMDSCs have never been studied, and only arginase 1 expression has been evaluated as a mechanism of M-MDSC-mediated immunosuppression. ${ }^{28,29}$ Here, we hypothesized that the increase in neutrophils and monocytes in peripheral blood of 
DLBCL patients might be related to an increase of G- and M- MDSCs. We found, using gene expression profiling (GEP), a myeloid suppressive signature in DLBCL peripheral blood. Accordingly, we identified an expansion in circulating G-MDSC and M-MDSC counts. Interestingly, M-MDSCs were immunosuppressive and correlated 


\section{Methods}

\section{Samples}

Two cohorts of patients were used in this study. For GEP, 76 DLBCL patients at diagnosis from the GOELAMS 075 clinical trial (clinicaltrials.gov: NCT00561379) and 87 matched healthy donors (HD) were enrolled. This cohort was already published by our group. ${ }^{6}$ Then, a prospective cohort was set with 66 DLBCL patients at diagnosis (BMS-LyTRANS study). Patients with previous corticosteroid treatment were excluded from this study. Forty-five age-matched HD were also enrolled. Clinical characteristics of DLBCL patients enrolled in this second cohort are listed in Table 1. The research protocol was conducted under French legal guidelines and fulfilled the requirements of the local institutional ethics committee.

\section{Whole blood GEP}

Whole blood was collected into PAXgene ${ }^{T M}$ Blood RNA tubes (Becton Dickinson BD Biosciences, San Jose, CA, USA) ensuring blood stabilization and stored at $-80^{\circ} \mathrm{C}$ before RNA extraction. High-quality total RNA was hybridized onto Affymetrix GeneChip® Human Exon 1.0 ST oligonucleotide arrays (Affymetrix, Santa Clara, CA, USA) according to manufacturer's instructions. Microarray Quality Control was assessed using Affymetrix Expression Control v1.1. Raw data were pre-filtered by selection of core-annotated probesets. Then, DABG (Detection Above BackGround) summary file was generated for the RMA normalized data using Affymetrix Power Tools. DABG calculates the $p$ value that the intensities in a probeset could have been observed by chance in a background distribution. A probeset was defined as present if its DABG p value was less than $5 \%$ in at least $50 \%$ of the samples in at least one condition. A transcript was preserved if at least $50 \%$ of the core probesets of the 
transcript were present. Pre-filtered data were RMA-normalized with adjustment for GC content and probesets were mean-summarized to transcripts (Partek® Genomics Suite $^{\mathrm{TM}}$ version 6.5, Partek Inc., St Louis, MO, USA). Unsupervised analysis using hierarchical clustering analysis ( $\mathrm{HCA})$ was performed on the normalized data. Differentially expressed genes were identified by the Mann-Whitney non-parametric test, with adjustment for multiple testing using the Benjamini-Hochberg False Discovery Rate set at 5\%. Array data are available in the Gene Expression Omnibus, accession number GSE83632. Interpretation of the functional roles was established using Ingenuity Pathway Analysis (IPA) (Ingenuity ${ }^{\circledR}$ Systems) based on the two genelists identified on the HCA as over- or under-expressed in DLBCL patients compared to HD. Canonical pathways analysis identified the pathways from the IPA knowledge database that were most significant to the data set (FDR $p<5 \%)$. Gene Set Enrichment Assay (GSEA) was performed using the BROAD Institute GSEA software (http://www.broad.mit.edu/gsea/) on the DLBCL dataset using a panel of genes that we defined as related to myeloid suppressive cells based on literature knowledge (Supplemental Table 1). ${ }^{30}$

\section{Quantitative real-time PCR}

Total RNA was extracted using PAXgene blood RNA kit (Qiagen, Valencia, CA, USA). cDNA was then generated using Multiscribe ${ }^{\circledR}$ Reverse Transcriptase and High-Capacity cDNA reverse Transcription kit (Invitrogen, Carlsbad, CA, USA). For quantitative RT-PCR, we used custom designed Taqman@ array microfluidic cards and the Taqman Universal Master Mix from Applied Biosystems (Invitrogen). Gene expression was measured by the ABI Prism $7900 \mathrm{HT}$ Sequence Detection System. 18S, CDKN1B and ELF1 were determined as appropriate internal standard genes 
using TaqMan endogenous control assays and geNorm algorithm analysis. For each sample, the CT value for the gene of interest was determined, normalized to the geometric mean value of the 3 housekeeping genes, and compared to the median value obtained from healthy donors using the 2-ddCT method. Results were expressed as the ratio of DLBCL mean to HD mean for each gene. Experiments were also performed on sorted CD14 ${ }^{\text {pos }} \mathrm{HLA}-\mathrm{DR}{ }^{\text {low }}$ or $\mathrm{CD} 14^{\text {pos }} \mathrm{HLA}-\mathrm{DR}{ }^{\text {high }}$ cells from three DLBCL peripheral blood. CDNA was prepared using Fluidigm Reverse Transcription Master Mix (Fluidigm, Sunnyvale, CA, USA). The qPCR was performed in triplicate using 96.96 Dynamic Array ${ }^{\mathrm{TM}}$ IFCs and the BioMark ${ }^{\mathrm{TM}}$ HD System from Fluidigm. For each $C D 14^{\text {pos }} \mathrm{HLA}-\mathrm{DR}^{\text {low }}$ sample, the mean CT value for the gene of interest was calculated, normalized to the geometric mean value of the 2 housekeeping genes, and compared to the median value obtained from CD14 ${ }^{\text {pos }} \mathrm{HLA}$ $\mathrm{DR}^{\text {high }}$ samples using the 2-ddCT method. Results were expressed as the ratio of CD14 ${ }^{\text {pos } H L A-D R ~}{ }^{\text {low }}$ mean to CD14 ${ }^{\text {pos }} H L A-D R^{\text {high }}$ mean for each gene.

\section{Fluorescent flow cytometry analysis}

Blood samples were collected on heparin tubes. Plasma specimens were stored at $-80^{\circ} \mathrm{C}$ until use. White blood cell (WBC) differential was performed using Cytodiff ${ }^{\mathrm{TM}}$ panel (CD36, CD2, CD294, CD19, CD16, CD45, Beckman Coulter, Brea, CA, USA) on $50 \mu \mathrm{L}$ of blood as previously described. ${ }^{31}$ Flow cytometry analysis of M-MDSCs,

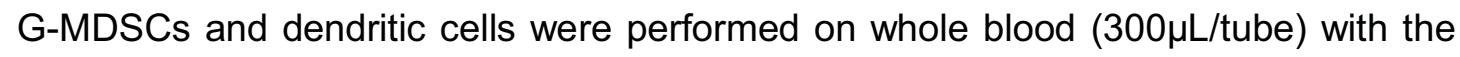
antibody panels described in Supplemental Table 2. Absolute counts were obtained by using Flow-Count beads (Beckman Coulter). An erythrocytes lysis (Uti-Lyse Dako, Carpinteria, CA, USA) was performed before analysis by flow cytometry (Navios, Beckman Coulter). G-MDSCs and M-MDSCs were identified as shown in 
Supplemental Figure 2 using Kaluza software (Beckman Coulter). $\mathrm{T}_{\text {reg }}$ and tumor circulating B-cells were defined on blood mononuclear cells (PBMC) after density gradient centrifugation (lymphocyte separation medium, Eurobio, CourtaBoeuf, France). For $\mathrm{T}_{\text {reg }}$ determination, cells were fixed and permeabilized using FOXP3 staining kit (BD Biosciences). Results were expressed as absolute values $\left(10^{6}\right.$ or $10^{9}$ cells/L), percentages or mean florescence intensity (MFI).

\section{Cytokines and enzymes assessment}

Concentrations of IL-10 (eBioscience, San Diego, CA, USA), TGF- $\beta 1$ (R\&D Systems, Minneapolis, MN, USA), S100A8/9, S100A12 and Arginase I (Hycult Biotech, Ude, The Netherlands) in the plasma or culture supernatants were measured by enzymelinked immunosorbent assay (ELISA), according to manufacturer's recommendations. Finally, arginase I and IDO activities were evaluated by highperformance liquid chromatography (HPLC) analysis ${ }^{32}$ as the ornithine to arginine and tryptophan to kynurenine ratio, respectively.

\section{T-cell proliferation assay}

Fresh PBMC from DLBCL or HD samples were separated into two fractions. The first fraction was positively depleted for residual erythrocytes using glycophorin $A$ beads (Miltenyi Biotech, Bergisch Gladbach, Germany) while the second fraction was depleted for erythrocytes and monocytes (CD14 microbeads, Miltenyi Biotech). The purity was higher than $97 \%$. The two negative fractions (PBMC and PBMC-CD14 ${ }^{\text {pos }}$ ) were labeled with $0.2 \mu \mathrm{M}$ carboxyfluorescein succinimidyl ester (CFSE; Interchim, Montlucon, France). PBMC and PBMC-CD14 ${ }^{\text {pos }}$ were plated in triplicate in 96-well round-bottom plates (Corning Costar, Corning, NY, USA) with RPMI 1640 medium 
enriched with $10 \%$ of human serum $A B$ (Biowest, Courtaboeuf, France) and $1 \%$ penicillin-streptomycin (Gibco, Saint Aubin, France). Then, cells were stimulated with soluble anti-CD3 $(0.6 \mu / \mathrm{mL}$, Sanquin, Amsterdam, The Netherlands) and anti-CD28 $\left(0.6 \mu / \mathrm{mL}\right.$, Sanquin) and cultured at $37^{\circ} \mathrm{C}$ in $5 \% \mathrm{CO} 2$ and $100 \%$ humidity for 4 days. For some experiments, $C D 3^{\text {pos }} \mathrm{T}$ cells were purified using magnetic beads (CD3 microbeads, Miltenyi Biotec), labeled with CFSE, and cocultured with autologous CD14 ${ }^{\text {pos } H L A-D R ~}{ }^{\text {low }}$ or CD14 ${ }^{\text {pos } H L A-D R ~}{ }^{\text {high }}$ sorted cells (FACS ARIA III; BD Biosciences) with a ratio of $2: 1$ in the presence of anti-CD3/anti-CD28 stimulation. CFSE dilution was assessed by flow cytometry and analyzed with ModFit LT software (Verity Software House, Topsham, ME, USA). Results were expressed by the proliferation index (PI).

\section{T-cell proliferation assay with inhibitors}

Cryopreserved PBMC from DLBCL patients depleted for residual erythrocytes were CFSE labeled and then platted in triplicate at $10^{6}$ cells $/ \mathrm{mL}$ in RPMI 1640 medium enriched with $10 \%$ of human serum $A B, 1 \%$ penicillin-streptomycin in 96 -well roundbottom plates and incubated at $37^{\circ} \mathrm{C}$ for 30 minutes with or without different neutralizing antibodies: anti-IL-10 (10 $\mathrm{g} / \mathrm{mL}, \mathrm{R} \& D$ systems); anti-S100A12 $(10 \mu \mathrm{g} / \mathrm{mL}$, Acris, San Diego, CA, USA) and anti-PD1 $(20 \mu \mathrm{g} / \mathrm{mL}$, clone 3.1 given by Professor Daniel Olive $)^{33}$ or with chemical analogs: L-1MT (1mM, Sigma-Aldrich, Diegem, Belgium $)^{34}$ and nor-NOHA (20mM, Enzo Life Sciences, Antwerpen, Belgium). At the concentration employed, nor-NOHA inhibited $>80 \%$ of the arginase 1 activity on a positive control (data not shown). Thereafter, cells were stimulated with soluble antiCD3 and anti-CD28 and incubated at $37^{\circ} \mathrm{C}$ in $5 \%$ CO2 and $100 \%$ humidity for 4 days. CFSE dilution was assessed by flow cytometry and analyzed with ModFit LT 
software. Results were expressed as the percentage of proliferation of inhibitortreated cells to control (anti-lgG1 isotype, 10 $\mathrm{g} / \mathrm{mL}$, R\&D or medium plus vehicle). DLBCL patients were classified into groups: without (Gr.1) or with (Gr.2) suppressive monocytes. The classification was based on suppressive assay or a number of $\mathrm{M}$ MDSCs at more than 3 fold the median count.

\section{Statistical analysis}

Statistical analyses were performed with GraphPad Prism 5.0 software (GraphPad Software, San Diego, CA, USA) using Spearman correlation, Wilcoxon or MannWhitney tests as appropriate. 


\section{Results}

\section{A myeloid regulatory GEP is detected in DLBCL peripheral blood}

GEP performed on whole blood was evaluated using the Affymetrix Human Exon $1.0 \mathrm{ST}$ Array on $76 \mathrm{DLBCL}$ patients and $87 \mathrm{HD}$. Following pre-filtering, the 11,302 remaining probesets (PS) were classified by an unsupervised hierarchical clustering. Sixty-five out of 76 DLBCL were clustered together with a set of 6,792 upregulated PS and a set of 4,510 downregulated PS compared to HD (Figure 1A). To further identify the immune response pathways affected in DLBCL, these PS were filtered ( $p<0.05$ and $|F C|>1.5$ ), highlighting 564 up- and 495 down-regulated PS in DLBCL compared to HD. These PS were further separately analyzed with IPA (Figure 1B). Within the 20 most represented pathways in DLBCL, we identified an innate immune response signature (TLR-, IL8-, IL6-, LPS-, TREM1-, NO/ROSsignaling), as well as an anti-inflammatory response (IL-10 signaling). On the other hand, a significant under-representation of pathways involved in T-cell activation (ICOS-ICOSL-, T cell receptor-, CD28-, CTLA4- signaling, regulation of IL-2 expression) was also revealed (Figure 1B). Then, by GSEA, we found in our DLBCL cohort a significant enrichment for a list of myeloid genes known to be upregulated in MDSCs $(p=0.03)$ (Supplemental Table 1 and Figure 1C). Finally, using the same list of myeloid genes (Supplemental Table 1), we performed a hierarchical clustering analysis on the 76 DLBCL samples (Supplemental Figure 1). A group of patients (Group B) with low expressions of MDSC-related genes (including ARG1, S100A12, S100A8, MMP8, SLPI, MPO, CD274, TNFAIP6, CxCL5 and AIM2) showed a better EFS probability than the other group of patients (Group A) $(p=0.013)$ (Figure 1D). Altogether these results were in favor of a myeloid regulatory signature in DLBCL with a clinical impact on patients' prognosis. 


\section{MDSCs are expanded in peripheral blood of DLBCL patients}

We next focused our attention on the quantitative modifications of myeloid cells in the peripheral blood of DLBCL patients. A new prospective cohort was set up with 66 DLBCL patients at diagnosis (BMS-LyTRANS study) as well as $45 \mathrm{HD}$ samples. We noticed in DLBCL a significant increase in the monocyte- (median: 0.51 vs $0.34 \times 10^{9} / \mathrm{L}, \quad \mathrm{p}=0.002$ ), neutrophil- (median: 3.69 vs $2.14 \times 10^{9} / \mathrm{L}, \mathrm{p}<0.0001$ ), and immature granulocyte- counts (median: 0.09 vs $0.03 \times 10^{9} / \mathrm{L}, \mathrm{p}=0.0003$ ) obtained on a regular complete blood count, whereas the white blood cell (WBC) counts were not different (Figure 2A). Tumor circulating B-cells were defined as $\mathrm{CD} 19^{\text {pos }} \mathrm{CD} 10^{\text {pos }} \mathrm{CD} 38^{\text {low }}$ and Kappa ${ }^{\text {pos }}$ or Lambda ${ }^{\text {pos }}$ and were detected in 9 out of 40 studied cases $(22.5 \%)$ with a median count at $0.48 \times 10^{9} / \mathrm{L}$ representing $0.16 \%$ to $25.3 \%$ of the WBC (data not shown). No correlation was found between tumor circulating cells and monocytes or granulocytes (data not shown). We found in patients with high risk ( $\mathrm{HR}$, age adapted aalPI $\geq 3)$ disease a decrease of the LMR and an increase of the NLR, when compared to low risk $(L R)$ patients $(p=0.044$ and 0.033, respectively) (Figure 2B).

As described in solid tumors ${ }^{22}$ and multiple myeloma, ${ }^{25}$ both granulocyte and monocyte compartments contain MDSC subsets. In $\mathrm{CLL}^{27}$ and $\mathrm{DLBCL}^{28,29}$ only MMDSCs were already detected in patients. Thus, we next evaluated the absolute count of circulating MDSCs and identified, in whole blood, G-MDSC $\left(\right.$ Lin $^{\text {neg }}{ }^{C D} 123^{\text {low }} \mathrm{HLA}-\mathrm{DR}{ }^{\text {neg }} \mathrm{CD} 33^{\text {pos }} \mathrm{CD} 11 \mathrm{~b}^{\text {pos }}$ ) and M-MDSC (CD14 $\left.{ }^{\text {pos }} \mathrm{HLA}-\mathrm{DR}{ }^{\text {low }}\right)$. MDSC counts were significantly increased in DLBCL compared to HD samples with a median count at 13 vs $6 \times 10^{6} / L(p=0.001)$ for G-MDSCs and 7.42 vs $2 \times 10^{6} / L(p=0.01)$ for M-MDSCs (Figure 2C). Interestingly, G-MDSCs and M-MDSCs correlate with 
immature granulocyte and monocyte counts $(p<0.0001$ and $p=0.03)$, respectively (Figure 2C). No correlation was found between G-MDSC and M-MDSC counts (data not shown). Finally, M-MDSCs were increased in HR- compared to LR- DLBCL $(p=0.049)$, and were associated with a worse EFS $(p=0.034, H R=0.19)$ (Figure 2D). G-MDSCs did not correlate with risk factors or EFS (data not shown). As the myeloid regulatory compartment in peripheral blood also includes dendritic cells, we assessed the 3 subsets of dendritic cells as follows: Lin ${ }^{\text {neg } H L A-~}$ $\mathrm{DR}^{\text {pos }} \mathrm{CD} 123^{\text {pos }} \mathrm{CD} 141^{\text {neg }} \mathrm{CD} 1 c^{\text {neg }} \mathrm{pDC}, \quad \mathrm{Lin}^{\text {neg }} \mathrm{HLA}-\mathrm{DR} \mathrm{R}^{\text {pos }} \mathrm{CD} 123^{\text {neg }} \mathrm{CD} 141^{\text {pos }} \mathrm{CD} 1 c^{\text {neg }}$ type $1 \mathrm{cDC}$, and $\operatorname{Lin}{ }^{\text {neg }} \mathrm{HLA}-\mathrm{DR}{ }^{\text {pos }} \mathrm{CD} 123^{\text {neg }} \mathrm{CD} 141^{\text {neg }} \mathrm{CD} 1 \mathrm{c}^{\text {pos }}$ type $2 \mathrm{cDC} .^{35}$ These cell types were significantly decreased in DLBCL when compared to HD, without correlation with any type of MDSCs (Supplemental Figure 3).

\section{M-MDSCs from DLBCL patients suppress T-cell response}

MDSC immunosuppressive activities lead to a T-cell proliferation blockade or apoptosis. Noteworthy T-cell count and the ratio of $C D 3 \zeta$ (CD247) to $C D 3 \gamma$ mRNA were decreased in DLBCL $(p=0.01$ and $p=0.0009$, respectively) (Figure 3A). Given the fact that i) in DLBCL, only M-MDSCs were correlated with prognostic, and ii) this subset has been described being the dominant suppressive population of MDSCs, ${ }^{24}$ we evaluated the suppressive capability of the monocyte fraction. We noticed that $C D 8^{\text {pos }} \mathrm{T}$ lymphocytes issued from DLBCL patients proliferated less than those from $\mathrm{HD}$ in response to polyclonal activation $(p=0.01)$ (Figure $3 B$ ). Interestingly, when CD14 ${ }^{\text {pos }}$ monocytes were depleted from PBMC, the proliferation index $(\mathrm{PI})$ ratio (monocyte-depleted PBMC to PBMC) was increased for DLBCL patients whereas it was decreased for HD demonstrating a specific suppressive activity for monocytes in lymphoma patients (Figure 3B). To evidence the specific in vitro suppressive capacity 
of $\mathrm{CD} 14^{\text {pos }} \mathrm{HLA}-\mathrm{DR}{ }^{\text {low }}$ cells, autologous $\mathrm{CD} 3^{\text {pos }} \mathrm{T}$ cells were stimulated in their presence or with CD14 ${ }^{\text {pos } H L A-D R ~}{ }^{\text {high }}$ cells. $C D 4^{\text {pos }}$ and $C D 8^{\text {pos }} \mathrm{T}$ cell proliferation index was lower in presence of $\mathrm{CD} 14^{\text {pos }} \mathrm{HLA}-\mathrm{DR}{ }^{\text {low }}$ cells compared to $\mathrm{DR}^{\text {high }}$ monocytes (Figure 3C). Then, by QPCR analysis performed on 3 DLBCL patients, we found a panel of genes involved in MDSC functions to be slightly increased in CD14 ${ }^{\text {pos }} \mathrm{HLA}-\mathrm{DR}^{\text {low }}$ compared to CD14 ${ }^{\text {pos }} \mathrm{HLA}-\mathrm{DR}^{\text {high }}$ (Figure 3D).

\section{In DLBCL, M-MDSC suppressive activity is independent from arginase I and} IDO activities

In B-cell malignancies, arginase 1 and IDO activities were reported in $\mathrm{DLBCL}^{29}$ and $\mathrm{CLL}^{27}$ respectively. MDSCs mediate T-cell suppression through various mechanisms. ${ }^{21}$ Therefore, we compared in DLBCL versus HD peripheral blood, the gene expression of 5 key enzymes (ARG1, IDO1, NOS2, HO-1 and PTGS2) involved in MDSC biology. Among those, only ARG1 was significantly increased in DLBCL $(p=0.003) . I D O 1$ although not significant, showed a trend of upregulation (1.8 fold $)$ in DLBCL (Figure 4A). To evaluate arginase 1 and IDO activities, we measured the concentration of arginine and tryptophan as well as their degradation products, ornithine and kynurenine, respectively. Arginase 1 and IDO activities were increased in DLBCL ( $p=0.02$ and $p=0.04$, respectively) (Figure 4B). Finally, we measured by ELISA the arginase 1 enzyme in plasma and found increased levels in DLBCL samples compared to HD (median at 157.4 vs $16.66 \mathrm{ng} / \mathrm{mL}, \mathrm{p}<0.0001$ ) (Figure $4 \mathrm{C}$ ). Then, based on the presence or absence of suppressive monocytes, 2 groups of DLBCL were constituted and we showed that in DLBCL the proliferation of CD4 $4^{\text {pos }}$ and $\mathrm{CD} 8^{\text {pos }}$ cells issued from PBMC was not increased in the presence of arginase or IDO inhibitors regardless of the presence of M-MDSCs (Figure 4D). Interestingly, 
arginase 1 in plasma did not correlate with M-MDSCs, but instead was correlated with the number of immature granulocytes, which contains G-MDSCs ${ }^{36} \quad(r=0.33$, $\mathrm{p}=0.049)$ (Figure 4E).

\section{IL-10, PDL-1 and S100A12 are involved in M-MDSC suppressive activity}

Because of the lack of correlation between M-MDSCs and arginase 1 or IDO in DLBCL, we sought for additional mechanisms of immunosuppression already described for MDSCs, including $T_{\text {reg }}$ induction, IL-10 and TGF $\beta$ release as well as PD-L1 expression. ${ }^{21}$ First, we found that $T_{\text {reg }}$ and M-MDSC counts were correlated in DLBCL patients $(r=0.5, p=0.039)$ (Figure $5 A)$. We then compared in DLBCL and HD peripheral blood, the gene expression of immunosuppressive molecules. IL10, S100A9 and S100A12 were significantly overexpressed in DLBCL unlike TGFB1 and S100A8. In addition, although not significant, CD274/PD-L1 was also increased in DLBCL by 1.85 fold (Figure 5B). Interestingly, although the expression of PD-L1 on M-MDSC was increased in DLBCL $(p=0.015)$ (Figure 5C), CD274 expression did not correlate with the circulating malignant B-cell count (data not shown). Similarly, IL-10 was increased at the protein level in DLBCL peripheral blood $(p<0.001)$, and a trend was also noticed for S100A12 ( $p=0.052)$ unlike TGF- $\beta 1$ and S100A8/A9 (Figure 5D). We thus evaluated the levels of IL-10 and S100A12 in culture supernatants from stimulated PBMC, depleted or not from CD14 ${ }^{\text {pos }}$ cells. These molecules were decreased after CD14 ${ }^{\text {pos }}$ depletion $(p<0.05)$ (Figure 5E). Finally, on the 2 groups of DLBCL classified depending on M-MDSC content, we analyzed the percentage of proliferating $\mathrm{T}$ cells after $\mathrm{CD} 3 / \mathrm{CD} 28$ stimulation in the presence of various blocking antibodies (IL-10, PD-1 and S100A12) (Figure 6). In the group of patients with 
circulating MDSC, neutralizing IL-10, PDL-1 and S100A12 resulted in an increase of CD4 and/or CD8 T-cell proliferation. 


\section{Discussion}

Circulating MDSCs have been described in various solid tumors with, in most cases, a predominance of G-MDSCs. ${ }^{22,23}$ Regarding lymphoid neoplasias, both G- and MMDSCs are increased in Hodgkin lymphoma and in multiple myeloma. ${ }^{25,37,38}$ Few studies were conducted on B-cell lymphomas or CLL which focused exclusively on the M-MDSC subtype. ${ }^{27-29,39}$ Since the majority of blood biomarkers in DLBCL are linked to tumor microenvironment and in particular to myeloid cell biology, ${ }^{6,7,14-17}$ further characterization of the MDSC compartment is highly relevant in this disease. Our aim, in this study, was to characterize the various MDSC subsets in peripheral blood from DLBCL patients.

As previously described we found an increase in neutrophil and monocyte counts, whereas the number of lymphocytes was reduced. This was also reflected in the whole blood GEP from DLBCL by an overexpression of myeloid-related genes and a downregulation of lymphoid-related genes. Additionally, we found enrichment in pathways involved in the innate immunity (TLR-, IL8-, IL6-, LPS-, TREM1-, NO/ROS- signaling) or in the anti-inflammatory response (IL-10 signaling).

Since there is no specific lineage marker, MDSC definitions are divergent, as such we explored by flow cytometry various panels on the first 15 patients: G-MDSC1 $\left(\right.$ Lin $^{\text {neg } H L A-D R ~}{ }^{\text {neg }}$ CD33 $\left.{ }^{\text {pos }} C D 11 b^{\text {pos }}\right)$,

G-MDSC2 $\left(\operatorname{Lin}^{\text {neg }} \mathrm{HLA}\right.$ $\left.\mathrm{DR}^{\text {neg }} \mathrm{CD} 33^{\text {pos }} \mathrm{CD} 11 \mathrm{~b}^{\text {pos }} \mathrm{CD} 34^{\text {pos }}\right)$, G-MDSC3 $\left(\right.$ Lin $^{\text {neg }} \mathrm{CD} 123^{\text {low }} \mathrm{HLA}-$ $\left.\mathrm{DR}^{\text {neg }} \mathrm{CD} 33^{\text {pos }} \mathrm{CD} 11 \mathrm{~b}^{\text {pos }}\right), \quad$ G-MDSC4 $\quad\left(\mathrm{SSC}^{\text {high }} \mathrm{CD66b^{ \text {pos } }}\right)$ and also: M-MDSC1 $\left(\mathrm{CD} 14^{\text {pos }} \mathrm{HLA}-\mathrm{DR} \mathrm{R}^{\text {low }}\right), \quad \mathrm{M}-\mathrm{MDSC} 2 \quad\left(\mathrm{CD} 14^{\text {pos }} \mathrm{CCR} 2^{\text {high }}\right), \quad$ M-MDSC3 $\left(C D 14^{\text {pos }} C D 163^{\text {pos }}\right) .{ }^{40,41}$ We retained the phenotype used in Figure 2 and Supplemental Figure 2 being the most informative (data not shown), in particular we found CD123 helpful in discarding polynuclear basophils during the gating strategy 
as their phenotype overlaps G-MDSCs. We then found higher counts of G-MDSCs $\left(\right.$ Lin $\left.^{\text {neg }} \mathrm{CD} 123^{\text {low }} \mathrm{HLA}-\mathrm{DR}{ }^{\text {neg }} \mathrm{CD} 33^{\text {pos }} \mathrm{CD} 11 \mathrm{~b}^{\text {pos }}\right)$. During the preparation of this manuscript and in agreement with our results, an expansion of myeloid cells with a G-MDSC phenotype has been reported in a small cohort of DLBCL patients $(n=5){ }^{42}$ In our study, G-MDSCs did not correlate with clinical outcomes, nor $\mathrm{T}_{\text {reg }}$ count. Additionally, the suppressive fraction of granulocyte was recently identified as remaining granulocytes in the PBMC fraction after density cell separation and called low density neutrophils. ${ }^{43}$ In DLBCL, G-MDSCs were detected only in whole blood but were absent from PBMC (data not shown). Thus, we focused our attention to MMDSCs.

M-MDSCs (CD14 $\left.{ }^{\text {pos } H L A-D R ~}{ }^{\text {low }}\right)$ were expanded in DLBCL patients, in concordance with 2 other studies with altogether 41 DLBCL patients. ${ }^{28,29}$ Finally, an additional monocyte subset $\left(\mathrm{CD} 14^{\mathrm{pos}} \mathrm{CD} 16^{\mathrm{pos}}\right)$ was found increased in DLBCL although partially overlapping with the M-MDSCs (data not shown). Whether, this latter subset displays suppressive function is controversial. For some authors, these cells do produce the anti-proliferative cytokine IL-10 or induce $T_{\text {reg, }}{ }^{44-46}$ whereas for others, they highly express HLA-DR and release the pro-inflammatory cytokine TNF$\alpha{ }^{47}$ One explanation might be their heterogeneity and gating challenge by flow cytometry, thus the $\mathrm{CD} 14^{\text {pos }} \mathrm{CD} 16^{\text {pos }}$ compartment likely contains different subsets including M-MDSCs. Interestingly, in our DLBCL cases, CD14 ${ }^{\text {pos }} C D 16^{\text {pos }}$ cells downregulated HLA-DR, a hallmark of MDSCs (data not shown). Altogether, our results were in favor of an increase in various MDSC subsets in DLBCL, with a clinical relevance for the M-MDSC population. In contrast to most solid tumors, where G-MDSCs are the predominant population of MDSCs, ${ }^{23}$ in lymphoid disease the MMDSCs are preeminent. ${ }^{27-29,39}$ M-MDSCs were recently defined, in tumor-bearing 
mice, as the most immunosuppressive subset. ${ }^{24}$ In DLBCL, we have shown that CD14 ${ }^{\text {pos }}$ cells exerted a suppressive activity on T cells which function and therefore proliferative activity can be restored after having depleted the CD14 ${ }^{\text {pos }}$ cells.

In lymphoid malignancies, arginase 1 and IDO are 2 mechanisms of suppression already described. ${ }^{27,29}$ In our study neither arginase 1, nor IDO activity were involved in the MDSC suppressive activity. The arginase 1 protein level was found highly expressed in the plasma without any relationship to M-MDSC subsets but rather correlated to the immature granulocyte fraction. Consequently, arginase 1 might likely be released by granulocytes but is not responsible for the M-MDSC suppressive activity. Two previous papers already reported an expansion of $\mathrm{M}$ MDSCs in DLBCL. One paper did not demonstrate functionally the suppressive activity of these cells, which is essential for the MDSC characterization. ${ }^{28}$ The second one did not focus on the DLBCL but rather involved a large variety of non-Hodgkin's lymphomas. Moreover, the functional assays were limited and excepted arginase 1 no other mechanisms of T-cell suppression were explored. ${ }^{29}$

These results prompted us to seek for additional suppressive mechanisms in MDSCs from DLBCL. Release of IL-10, TGF- $\beta$ and activation of the PD-L1/PD-1 axis are known MDSC mechanisms of suppression. ${ }^{48-51}$ Interestingly, in DLBCL we and others have shown that IL-10 and SPD-L1 can be elevated compared to HD. ${ }^{6,52}$ Herein, we demonstrated that monocyte suppressive activity was mediated by a release of IL-10 by CD14 ${ }^{\text {pos }}$ cells and an expression of PD-L1 on monocytes. These suppressive activities were impaired by neutralizing antibodies. ${ }^{53}$ Nevertheless, in most DLBCL we found beside G- and M-MDSC, an increase of neutrophils, immature granulocytes and monocytes potentially including suppressive subsets, thus we cannot rule out that the mechanisms described in our study could be shared between 
various subsets. We also demonstrated that $\mathrm{S} 100 \mathrm{~A} 12$ is responsible for T-cell suppression in DLBCL. In accordance with this finding, S100A8, S100A9 and S100A12 are expressed in MDSCs from hepatocellular and colorectal carcinomas, ${ }^{54,55}$ and $\mathrm{S} 100$ proteins, among other abilities, enhance the suppressive activity of MDSCs via an increase in ROS production. ${ }^{56-58}$ The number of $\mathrm{T}_{\text {reg, }}$, another mediator of T-cell proliferation arrest was correlated with M-MDSC count but not with G-MDSC count. Taken altogether, our results indicate that several regulatory mechanisms might be involved by MDSCs to block the immune response in DLBCL patients.

Here, we demonstrated that in DLBCL at diagnosis, M-MDSCs are predominant and are correlated with a worse prognosis. It would be interesting to monitor these populations during the course of the treatment, indeed accumulation or depletion of MDSCs is influenced by chemotherapy and/or immunotherapy. ${ }^{59}$ Our study also point out the potential interest of MDSCs as targets in future therapeutic trials on DLBCL patients. Controlling the expansion and accumulation of MDSCs or blocking their suppressive functions for instance by $\mathrm{CSF}-\mathrm{R} 1^{60}$ or $\mathrm{S} 100$ family member ${ }^{61}$ targeting represents promising novel approaches in cancer therapy. 


\section{Acknowledgments}

This work was supported by a research grant from the National Institute of Cancer (INCa Recherche Translationnelle 2010), by the Groupe Ouest-Est des Leucémies et des Autres Maladies du Sang (GOELAMS), by the LYSA group and by the Ligue Nationale Contre le Cancer (équipe labellisée). MR is a recipient of a fellowship from the Nuovo-Soldati Fundation. We are indebted to the clinicians of the BREHAT network and to the French Blood Bank (EFS) of Rennes for providing samples. The authors acknowledge the Centre de Ressources Biologiques (CRB-santé) of Rennes (BB-0033-00056, http://www.crbsante-rennes.com) for managing samples. Affymetrix microarrays were processed in the Microarray Core Facility of the Institute of Research on Biotherapy, CHRU-INSERM-UM1 Montpellier, http://irb.chumontpellier.frl. We are thankful to Professor Daniel Olive (INSERM 1068, Marseille, France) for the gift of the neutralizing anti-PD-1.

\section{Authors contributions}

IA: designed and performed experiments, analyzed data, and contributed writing; FU: designed and performed experiments and analyzed data; DR, CP, JD, JLP: analyzed data; TL, RH, SLG, GC, PG, KB, NM, GD: provided samples; KT, TF: raised the funds, designed and supervised research, analyzed data and contributed writing; MR: designed and supervised research, analyzed data, and wrote the paper. All authors revised the manuscript.

\section{Conflict-of interest disclosure}

All authors declare no conflicts of interest. 


\section{Reference}

1. World Health Organization. WHO Classification of Tumours of Haematopoietic and Lymphoid Tissues. Lyon, France: International Agency for Research on Cancer; 2008.

2. Vaidya R, Witzig TE. Prognostic factors for diffuse large B-cell lymphoma in the $\mathrm{R}(\mathrm{X}) \mathrm{CHOP}$ era. Annals of Oncology. 2014;25(11):2124-2133.

3. A Predictive Model for Aggressive Non-Hodgkin's Lymphoma. $N$ Engl J Med. 1993;329(14):987-994.

4. Sehn LH, Gascoyne RD. Diffuse large B-cell lymphoma: optimizing outcome in the context of clinical and biologic heterogeneity. Blood. 2015;125(1):22-32.

5. Zhou Z, Sehn LH, Rademaker AW, et al. An enhanced International Prognostic Index (NCCN-IPI) for patients with diffuse large B-cell lymphoma treated in the rituximab era. Blood. 2014;123(6):837-842.

6. Rossille D, Gressier M, Damotte D, et al. High level of soluble programmed cell death ligand 1 in blood impacts overall survival in aggressive diffuse large BCell lymphoma: results from a French multicenter clinical trial. Leukemia. 2014;28(12):2367-2375.

7. Charbonneau B, Maurer MJ, Ansell SM, et al. Pretreatment circulating serum cytokines associated with follicular and diffuse large B-cell lymphoma: A clinicbased case-control study. Cytokine. 2012;60(3):882-889.

8. Alizadeh AA, Eisen MB, Davis RE, et al. Distinct types of diffuse large B-cell lymphoma identified by gene expression profiling. Nature. 2000;403(6769):503-511.

9. Alizadeh AA, Gentles AJ, Alencar AJ, et al. Prediction of survival in diffuse large B-cell lymphoma based on the expression of 2 genes reflecting tumor and microenvironment. Blood. 2011;118(5):1350-1358.

10. Horn $\mathrm{H}$, Ziepert M, Becher $\mathrm{C}$, et al. MYC status in concert with BCL2 and BCL6 expression predicts outcome in diffuse large B-cell lymphoma. Blood. 2013;121(12):2253-2263.

11. Coutinho R, Clear AJ, Mazzola E, et al. Revisiting the immune microenvironment of diffuse large B-cell lymphoma using a tissue microarray and immunohistochemistry: robust semi-automated analysis reveals CD3 and FoxP3 as potential predictors of response to R-CHOP. Haematologica. 2015;100(3):363-369.

12. Keane C, Gill D, Vari F, et al. CD4(+) tumor infiltrating lymphocytes are prognostic and independent of R-IPI in patients with DLBCL receiving R-CHOP chemo-immunotherapy. Am J Hematol. 2013;88(4):273-276.

13. Lenz G, Wright G, Dave SS, et al. Stromal gene signatures in large-B-cell lymphomas. N Engl J Med. 2008;359(22):2313-2323.

14. Riihijarvi S, Fiskvik I, Taskinen M, et al. Prognostic influence of macrophages in patients with diffuse large B-cell lymphoma: a correlative study from a Nordic phase II trial. Haematologica. 2015;100(2):238-245.

15. Troppan K, Deutsch A, Gerger A, et al. The derived neutrophil to lymphocyte ratio is an independent prognostic factor in patients with diffuse large B-cell lymphoma. British Journal of Cancer. 2014;110(2):369-374.

16. Wilcox RA, Ristow K, Habermann TM, et al. The absolute monocyte and lymphocyte prognostic score predicts survival and identifies high-risk patients in diffuse large-B-cell lymphoma. Leukemia. 2011;25(9):1502-1509.

17. Tadmor T, Bari A, Sacchi S, et al. Monocyte count at diagnosis is a prognostic parameter in diffuse large B-cell lymphoma: results from a large multicenter 
study involving 1191 patients in the pre- and post-rituximab era. Haematologica. 2014;99(1):125-130.

18. Solito S, Marigo I, Pinton L, et al. Myeloid-derived suppressor cell heterogeneity in human cancers. Ann. N. Y. Acad. Sci. 2014;1319(1):47-65.

19. Gabrilovich DI, Nagaraj S. Myeloid-derived suppressor cells as regulators of the immune system. Nat Rev Immunol. 2009;9(3):162-174.

20. Parker KH, Beury DW, Ostrand-Rosenberg S. Myeloid-Derived Suppressor Cells: Critical Cells Driving Immune Suppression in the Tumor Microenvironment. Adv. Cancer Res. 2015;128:95-139.

21. Gabrilovich DI, Ostrand-Rosenberg S, Bronte V. Coordinated regulation of myeloid cells by tumours. Nat Rev Immunol. 2012;12(4):253-268.

22. Greten TF, Manns MP, Korangy F. Myeloid derived suppressor cells in human diseases. Int Immunopharmacol. 2011;11(7):802-807.

23. Youn J-I, Kumar V, Collazo M, et al. Epigenetic silencing of retinoblastoma gene regulates pathologic differentiation of myeloid cells in cancer. Nature Immunology. 2013;14(3):211-220.

24. Haverkamp JM, Smith AM, Weinlich R, et al. Myeloid-derived suppressor activity is mediated by monocytic lineages maintained by continuous inhibition of extrinsic and intrinsic death pathways. Immunity. 2014;41(6):947-959.

25. Görgün GT, Whitehill G, Anderson JL, et al. Tumor-promoting immunesuppressive myeloid-derived suppressor cells in the multiple myeloma microenvironment in humans. Blood. 2013;121(15):2975-2987.

26. Wilcox RA, Feldman AL, Wada DA, et al. B7-H1 (PD-L1, CD274) suppresses host immunity in T-cell lymphoproliferative disorders. Blood. 2009;114(10):2149-2158.

27. Jitschin R, Braun M, Büttner M, et al. CLL-cells induce IDOhi CD14+HLA-DRlo myeloid-derived suppressor cells that inhibit T-cell responses and promote TRegs. Blood. 2014;124(5):750-760.

28. Tadmor T, Fell R, Polliack A, Attias D. Absolute monocytosis at diagnosis correlates with survival in diffuse large B-cell lymphoma-possible link with monocytic myeloid-derived suppressor cells. Hematol Oncol. 2013;31(2):6571.

29. Lin Y, Gustafson MP, Bulur PA, et al. Immunosuppressive CD14+HLA-DRlow/monocytes in B-cell non-Hodgkin lymphoma. Blood. 2011;117(3):872-881.

30. Subramanian A, Tamayo P, Mootha VK, et al. Gene set enrichment analysis: a knowledge-based approach for interpreting genome-wide expression profiles. Proc. Natl. Acad. Sci. U.S.A. 2005;102(43):15545-15550.

31. Roussel M, Benard C, Ly-Sunnaram B, Fest T. Refining the white blood cell differential: the first flow cytometry routine application. Cytometry $A$. 2010;77(6):552-563.

32. Tattevin P, Monnier D, Tribut $\mathrm{O}$, et al. Enhanced indoleamine 2,3-dioxygenase activity in patients with severe sepsis and septic shock. J. Infect. Dis. 2010;201(6):956-966.

33. Thibult M-L, Mamessier E, Gertner-Dardenne J, et al. PD-1 is a novel regulator of human B-cell activation. Int Immunol. 2013;25(2):129-137.

34. Maby-El Hajjami H, Amé-Thomas P, Pangault C, et al. Functional alteration of the lymphoma stromal cell niche by the cytokine context: role of indoleamine2,3 dioxygenase. Cancer Research. 2009;69(7):3228-3237.

35. Ziegler-Heitbrock L, Ancuta P, Crowe S, et al. Nomenclature of monocytes and dendritic cells in blood. Blood. 2010;116(16):e74-80. 
36. Solito S, Falisi E, Diaz-Montero CM, et al. A human promyelocytic-like population is responsible for the immune suppression mediated by myeloidderived suppressor cells. Blood. 2011;118(8):2254-2265.

37. Romano $A$, Parrinello NL, Vetro $C$, et al. Circulating myeloid-derived suppressor cells correlate with clinical outcome in Hodgkin Lymphoma patients treated up-front with a risk-adapted strategy. British Journal of Haematology. 2015;168(5):689-700.

38. Brimnes MK, Vangsted AJ, Knudsen LM, et al. Increased level of both CD4+FOXP3+ regulatory $T$ cells and CD14+HLA-DR-/low myeloid-derived suppressor cells and decreased level of dendritic cells in patients with multiple myeloma. Scand J Immunol. 2010;72(6):540-547.

39. Giannoni P, Pietra G, Travaini G, et al. Chronic lymphocytic leukemia nurselike cells express hepatocyte growth factor receptor (c-MET) and indoleamine 2,3-dioxygenase and display features of immunosuppressive type 2 skewed macrophages. Haematologica. 2014;99(6):1078-1087.

40. Walter S, Weinschenk T, Stenzl A, et al. Multipeptide immune response to cancer vaccine IMA901 after single-dose cyclophosphamide associates with longer patient survival. Nat Med. 2012;18(8):1254-1261.

41. Mandruzzato S, Brandau S, Britten CM, et al. Toward harmonized phenotyping of human myeloid-derived suppressor cells by flow cytometry: results from an interim study. Cancer Immunol Immunother. 2016;65(2):161-169.

42. Gustafson MP, Lin Y, Maas ML, et al. A method for identification and analysis of non-overlapping myeloid immunophenotypes in humans. PLOS ONE. 2015;10(3):e0121546.

43. Sagiv JY, Michaeli J, Assi S, et al. Phenotypic Diversity and Plasticity in Circulating Neutrophil Subpopulations in Cancer. Cell Rep. 2015;10(4):562573.

44. Liu B, Dhanda A, Hirani S, et al. CD14++CD16+ Monocytes Are Enriched by Glucocorticoid Treatment and Are Functionally Attenuated in Driving Effector T Cell Responses. The Journal of Immunology. 2015;194(11):5150-5160.

45. Cros J, Cagnard N, Woollard K, et al. Human CD14dim Monocytes Patrol and Sense Nucleic Acids and Viruses via TLR7 and TLR8 Receptors. Immunity. 2010;33(3):375-386.

46. Skrzeczyńska-Moncznik J, Bzowska M, Loseke S, et al. Peripheral blood CD14high CD16+ monocytes are main producers of IL-10. Scand J Immunol. 2008;67(2):152-159.

47. Belge KU, Dayyani F, Horelt A, et al. The Proinflammatory CD14+CD16+DR++ Monocytes Are a Major Source of TNF. The Journal of Immunology. 2002;168(7):3536-3542.

48. Huang B, Pan P-Y, Li Q, et al. Gr-1+CD115+ immature myeloid suppressor cells mediate the development of tumor-induced $\mathrm{T}$ regulatory cells and T-cell anergy in tumor-bearing host. Cancer Research. 2006;66(2):1123-1131.

49. Ghiringhelli F, Puig PE, Roux S, et al. Tumor cells convert immature myeloid dendritic cells into TGF-beta-secreting cells inducing CD4+CD25+ regulatory $T$ cell proliferation. J Exp Med. 2005;202(7):919-929.

50. Filipazzi P, Valenti R, Huber V, et al. Identification of a New Subset of Myeloid Suppressor Cells in Peripheral Blood of Melanoma Patients With Modulation by a Granulocyte-Macrophage Colony-Stimulation Factor-Based Antitumor Vaccine. J Clin Oncol. 2007;25(18):2546-2553.

51. Chikamatsu K, Sakakura K, Toyoda M, et al. Immunosuppressive activity of 
CD14+ HLA-DR- cells in squamous cell carcinoma of the head and neck. Cancer Sci. 2012;103(6):976-983.

52. Gupta M, Han JJ, Stenson M, et al. Elevated serum IL-10 levels in diffuse large B-cell lymphoma: a mechanism of aberrant JAK2 activation. Blood. 2012;119(12):2844-2853.

53. Nguyen LT, Ohashi PS. Clinical blockade of PD1 and LAG3 -potential mechanisms of action. Nat Rev Immunol. 2015;15(1):45-56.

54. Zhao F, Hoechst B, Duffy A, et al. S100A9 a new marker for monocytic human myeloid-derived suppressor cells. Immunology. 2012;136(2):176-183.

55. Höchst B, Schildberg FA, Sauerborn $P$, et al. Activated human hepatic stellate cells induce myeloid derived suppressor cells from peripheral blood monocytes in a CD44-dependent fashion. J. Hepatol. 2013;59(3):528-535.

56. Bresnick AR, Weber DJ, Zimmer DB. S100 proteins in cancer. Nat Rev Cancer. 2015;15(2):96-109.

57. Meijer B, Gearry RB, Day AS. The Role of S100A12 as a Systemic Marker of Inflammation. International Journal of Inflammation. 2012;2012(2):1-6.

58. Lim SY, Raftery MJ, Goyette J, Hsu K, Geczy CL. Oxidative modifications of S100 proteins: functional regulation by redox. Journal of Leukocyte Biology. 2009;86(3):577-587.

59. Galluzzi L, Buqué A, Kepp O, Zitvogel L, Kroemer G. Immunological Effects of Conventional Chemotherapy and Targeted Anticancer Agents. Cancer Cell. 2015;28(6):690-714.

60. Xu J, Escamilla J, Mok S, et al. CSF1R Signaling Blockade Stanches TumorInfiltrating Myeloid Cells and Improves the Efficacy of Radiotherapy in Prostate Cancer. Cancer Research. 2013;73(9):2782-2794.

61. Qin H, Lerman B, Sakamaki I, et al. Generation of a new therapeutic peptide that depletes myeloid-derived suppressor cells in tumor-bearing mice. Nat Med. 2014;20(6):676-681. 


\section{Figure Legends}

Figure 1. A myeloid transcriptomic signature is detected in blood of DLBCL patients. (A) Hierarchical clustering of $76 \mathrm{DLBCL}$ and $87 \mathrm{HD}$. After raw data normalization and pre-filtering, 11,302 PS were classified by an unsupervised hierarchical clustering. Up- (yellow) and down-regulated (orange) gene lists were separately analyzed by IPA for canonical pathways. (B) Genes were filtered $(p<0.05$ and $|\mathrm{FC}|>1.5)$ before IPA analysis and the top 20 significant pathways are shown for both gene lists. (C) GSEA plot in the studied cohort for a list of gene involved in MDSCs (see Supplemental Table 1). Genes were ranked by signal to noise ratio. (D) With the same list of genes, the 76 DLBCLs were classified by an unsupervised hierarchical clustering, in group B with low expression of MDSC-related genes (see Supplemental Figure 1) or in group A. The event-free survival probability was calculated for both groups with a log-rank test.

Figure 2. MDSC-like subsets accumulate in peripheral blood of DLBCL patients but only M-MDSCs correlate with the clinical status of DLBCL patients. (A) Neutrophils, immature granulocytes (Imm Gran), monocytes as determined on a complete blood count and WBC counts are shown for 45 healthy donors (HD) and 66 DLBCL samples. Box and Whisker plots with the 10-90 percentiles and the outliers are shown. (B) DLBCL patients were separated in low- $(L R, n=16)$ or high-risk $(H R$, $n=34$ ) group based on the aalPI score ( $<3$ and $\geq 3$, respectively). Lymphocyte to monocyte (LMR) and neutrophil to lymphocyte (NLR) ratio are shown. (C) Left: GMDSC and M-MDSC counts were performed in $23 \mathrm{HD}$ and 31 DLBCL samples. Right: Correlation (Spearman) between G-MDSC and Imm Gran counts, and between M-MDSC and monocytes counts. (D) For 29 DLBCL samples, clinical information was available. Top: Patients were separated in a low- $(L R, n=12)$ or highrisk (HR, $n=17$ ) group based on the aalPI score ( $<3$ and $\geq 3$, respectively). M-MDSCs are shown for these groups. Bottom: Patients were split up between high- $(n=14)$ and low- $(n=15)$ count of M-MDSC (with a threshold at the median count) and the eventfree survival probability was calculated for both groups with a log-rank test. * $p<0.05$, ${ }^{* *} p<0.01,{ }^{* * *} p<0.001$. 
Figure 3. M-MDSCs are immunosuppressive in DLBCL. (A) Left: T-cell count. Right: ratio of $C D 3 \zeta$ to $C D 3 \gamma$ mRNA evaluated by RT-qPCR (TLDA). Box and Whisker plots with the $10-90$ percentiles and the outliers are shown. ${ }^{*} p<0.05$, ${ }^{* *}$ $p<0.001$. (B) Activated CFSE-labeled $T$ lymphocytes were cultured in presence (PBMC) or absence (PBMC - monocyte) of autologous monocyte isolated from DLBCL patients and HD. Proliferation index for $\mathrm{CD}^{\text {pos }}$ (top) and $\mathrm{CD}^{\text {pos }}$ (bottom) cells in presence of autologous monocyte (PBMC) or after monocyte depletion (PBMC - monocyte) are represented on Box and Whisker plots with the 10-90 percentiles and the outliers ( $n=10$ DLBCL and $n=8 \mathrm{HD}$ ). Wilcoxon (dashed line) or Mann-Whitney (solid line) tests were used for paired non-parametric and non-paired non-parametric analyses, respectively. (C) Activated CFSE-labeled T lymphocytes were cultured in presence of autologous sorted M-MDSC (HLA-DR ${ }^{\text {low }}$ ) or monocyte $\left(H L A-D R^{\text {high }}\right)$ isolated from DLBCL patients $(n=7)$. Proliferation index for $\mathrm{CD}^{\text {pos }}$ (top) and $C D 8^{\text {pos }}$ (bottom) cells are represented on Box and Whisker plots with the 10-90 percentiles. (D) Gene expression evaluated by QPCR on CD14 ${ }^{\text {pos } H L A-D R ~}{ }^{\text {low }}$ and CD14 ${ }^{\text {pos } H L A-D R ~}{ }^{\text {high }}$ cells sorted from 3 DLBCL. For each gene, the relative expression (mRNA) of CD14 ${ }^{\text {pos }} \mathrm{HLA}-\mathrm{DR}{ }^{\text {low }}$ and $\mathrm{CD} 14^{\text {pos }} \mathrm{HLA}-\mathrm{DR}{ }^{\text {high }}$ PBMC was compared (ratio of the mean expression on $C D 14^{\text {pos }} \mathrm{HLA}-\mathrm{DR}{ }^{\text {low }}$ to the mean expression on CD14 $\left.{ }^{\text {pos } H L A-D R ~}{ }^{\text {high }}\right)$. ns: non significant * $p<0.05$.

Figure 4. Arginase 1 and IDO are not M-MDSCs mechanisms of immunosuppression in DLBCL. (A) Expression of ARG1, IDO1, NOS2, HO-1 and PTGS2 was evaluated by TLDA on $17 \mathrm{DLBCL}$ and $15 \mathrm{HD}$ samples. The relative gene expression (mRNA) of PBMC from DLBCL and HD was compared (ratio of the mean expression on DLBCL to the mean expression on HD). (B) Arginase 1 and IDO activities were evaluated by HPLC with the ratio ornithine to arginine and kynurenine to tryptophan, respectively ( $n=31 \mathrm{DLBCL}$ and $21 \mathrm{HD}$ ). (C) Arginase 1 in plasma was evaluated by ELISA ( $n=43$ DLBCL and $33 \mathrm{HD}$ ). ${ }^{*} p<0.05,{ }^{* *} p<0.01,{ }^{* * *} p<0.001$. (D) Percentage of increase or decrease in T-cell proliferation (proliferation index) between treated ( $\mathrm{L}-1 \mathrm{MT}$ or nor-NOHA) and untreated cells, evaluated for $\mathrm{CD} 4^{\text {pos }}$ and $C D 8^{\text {pos }}$ cells by CFSE labeling ( $n=8$ DLBCL for $L-1 M T$ and $n=7$ for nor-NOHA). DLBCL patients were classified into groups: without $(\mathrm{Gr} .1, \mathrm{n}=5)$ or with $(\mathrm{Gr} .2, \mathrm{n}=2$ or 3 ) suppressive monocytes. The classification was based on suppressive assay or a number of M-MDSCs at more than 3 fold the median count. (E) Correlation of the 
arginase 1 in plasma and M-MDSC count (left) or immature granulocytes count (Imm gran) (right) count in DLBCL peripheral blood ( $n=36$ DLBCL). ns: not significant.

Figure 5. In DLBCL, IL-10, PD-L1 and S100A9/12 are expressed by monocytes.

(A) Correlation of the $T_{\text {reg }}$ and M-MDSC counts in DLBCL peripheral blood $(n=17)$.

(B) Expression of the immunomodulatory genes IL10, TGF $\beta 1, C D 274, S 100 A 8$, S100A9, S100A12 evaluated by TLDA. The relative gene expression (mRNA) of PBMC from DLBCL and HD was compared (ratio of the mean expression on DLBCL to the mean expression on HD) ( $n=17$ DLBCL and 15 HD). (C) Surface PD-L1 by flow cytometry expressed as ratio of mean fluorescence intensity (rMFI) for CD14 ${ }^{\text {pos } H L A-D R ~}{ }^{\text {low }}$ to CD14 ${ }^{\text {pos }} \mathrm{HLA}-\mathrm{DR}^{\text {high }}$ ( $\mathrm{n}=13 \mathrm{DLBCL}$ and 8 HD). (D) Cytokines detection by ELISA in HD $(n=8)$ and DLBCL plasma: IL-10 ( $n=45)$, TGF- $\beta \quad(n=14)$, S100A8/9 ( $n=14)$, S100A12 ( $n=14)$. (E) Cytokines (IL-10 and S100A12) detection by ELISA in supernatants of PBMC not depleted $(+)$ or depleted $(-)$ in CD14 ${ }^{\text {pos }}$ cells $\left(n=13\right.$ DLBCL). ${ }^{*} p<0.05,{ }^{* *} p<0.01,{ }^{* *} p<0.001$.

Figure 6. In DLBCL, IL-10, PDL-1 and S100A12 are involved in M-MDSC suppressive activity. DLBCL patients were classified into groups: without (Gr.1, $\mathrm{n}=5)$ or with $(\mathrm{Gr} .2, \mathrm{n}=4)$ suppressive monocytes based on suppressive assay or a number of M-MDSCs at more than 3 fold the median count. The percentage of increase or decrease in T-cell proliferation (proliferating index) between cells treated by blocking antibodies (anti -IL-10, -PD-1 and -S100A12) and an irrelevant antibody is shown for $C D 4^{\text {pos }}$ and $C D 8^{\text {pos }}$ cells. * $p<0.05$. 
Table 1: Patients characteristics of the BMS-LyTRANS cohort

\begin{tabular}{|cc} 
& $\begin{array}{c}\text { BMS-LyTRANS cohort } \\
(\mathbf{n}=66)\end{array}$ \\
\hline Average age, years & 53.9 \\
Male, $\mathbf{n}(\%)$ & $35(53.0)$ \\
Female, $\mathbf{n}(\%)$ & $31(47.0)$ \\
IPI, $\mathbf{n}(\%)$ & \\
0 to 1 & $22(33.3)$ \\
2 & $13(19.7)$ \\
3 & $21(31.8)$ \\
4 to 5 & $10(15.2)$ \\
Cell of origin, $\mathbf{n}(\%)$ & \\
GCB & $16(61.5)^{*}$ \\
Non-GCB & $10(38.4)^{*}$ \\
\hline Unknown & 49 \\
\hline *: percentage among cases with results
\end{tabular}



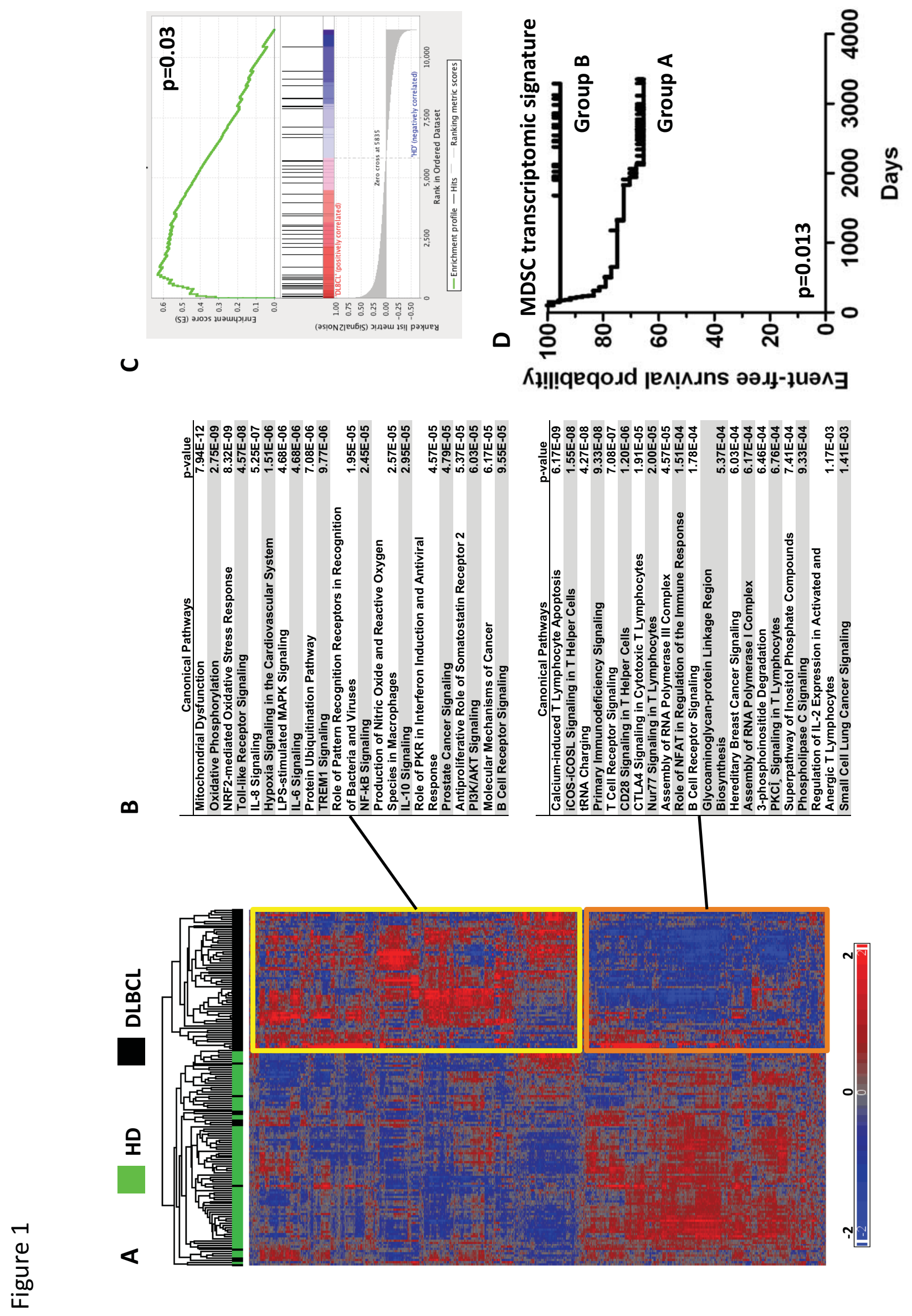

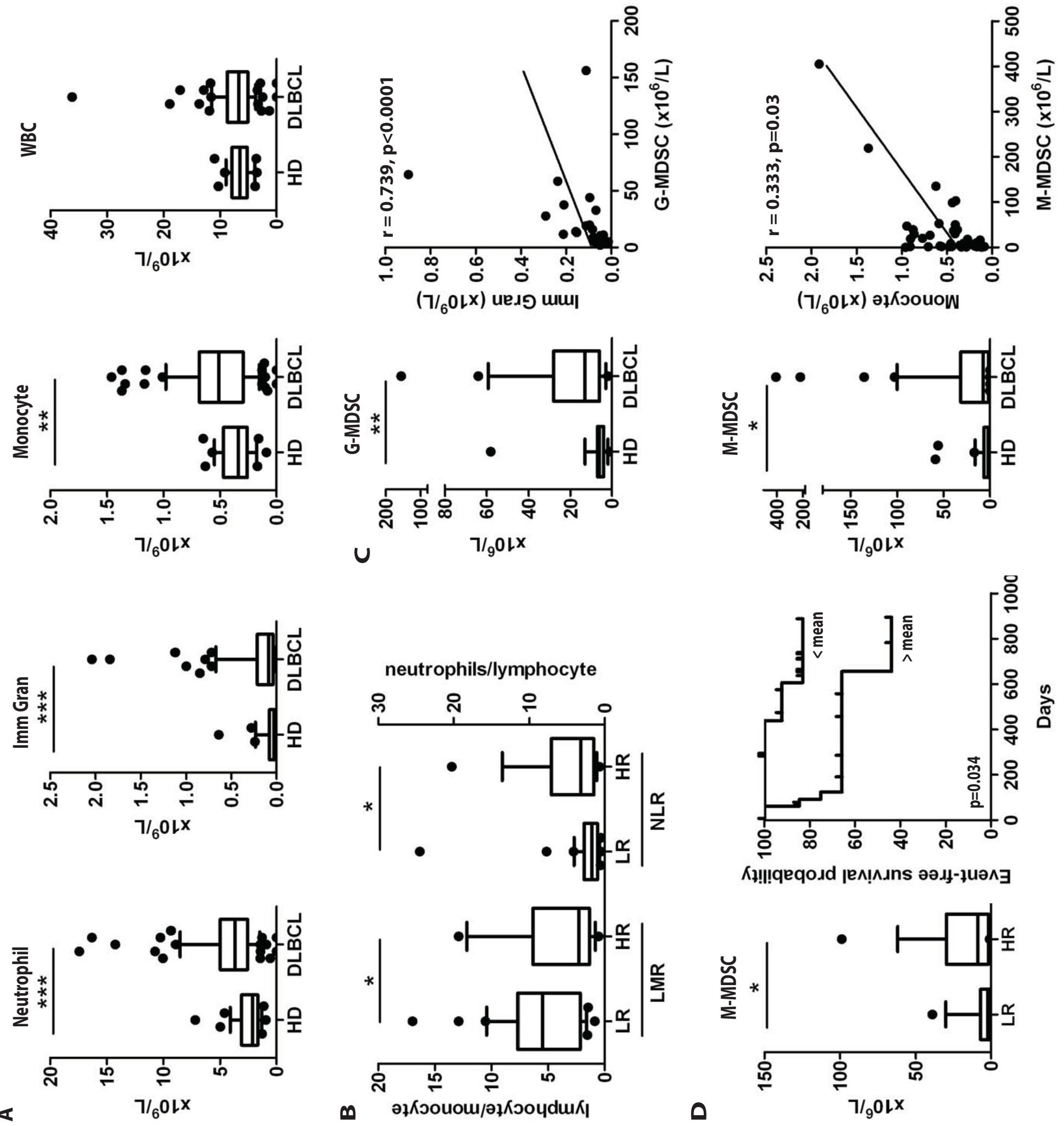
Figure 3

A

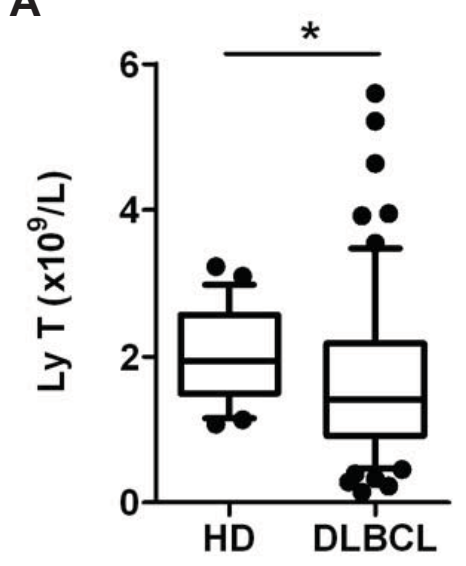

B
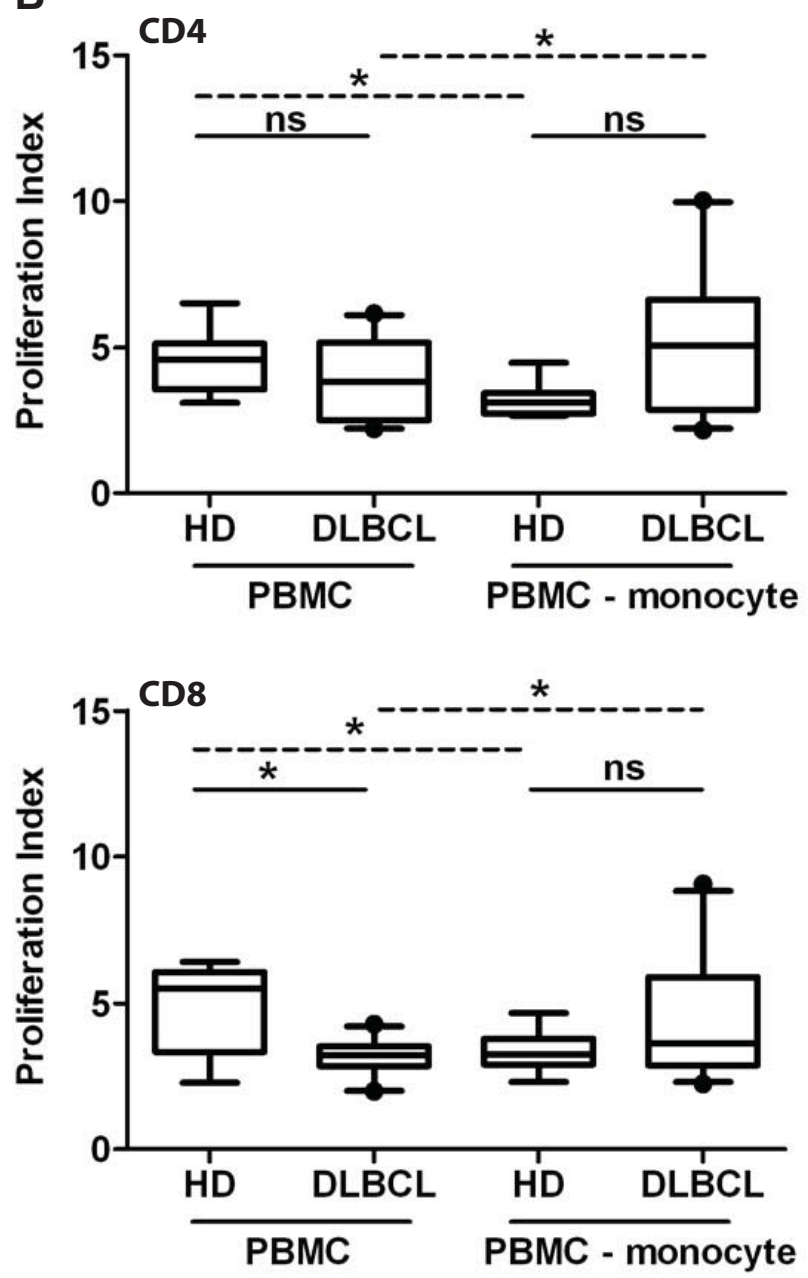

D

C
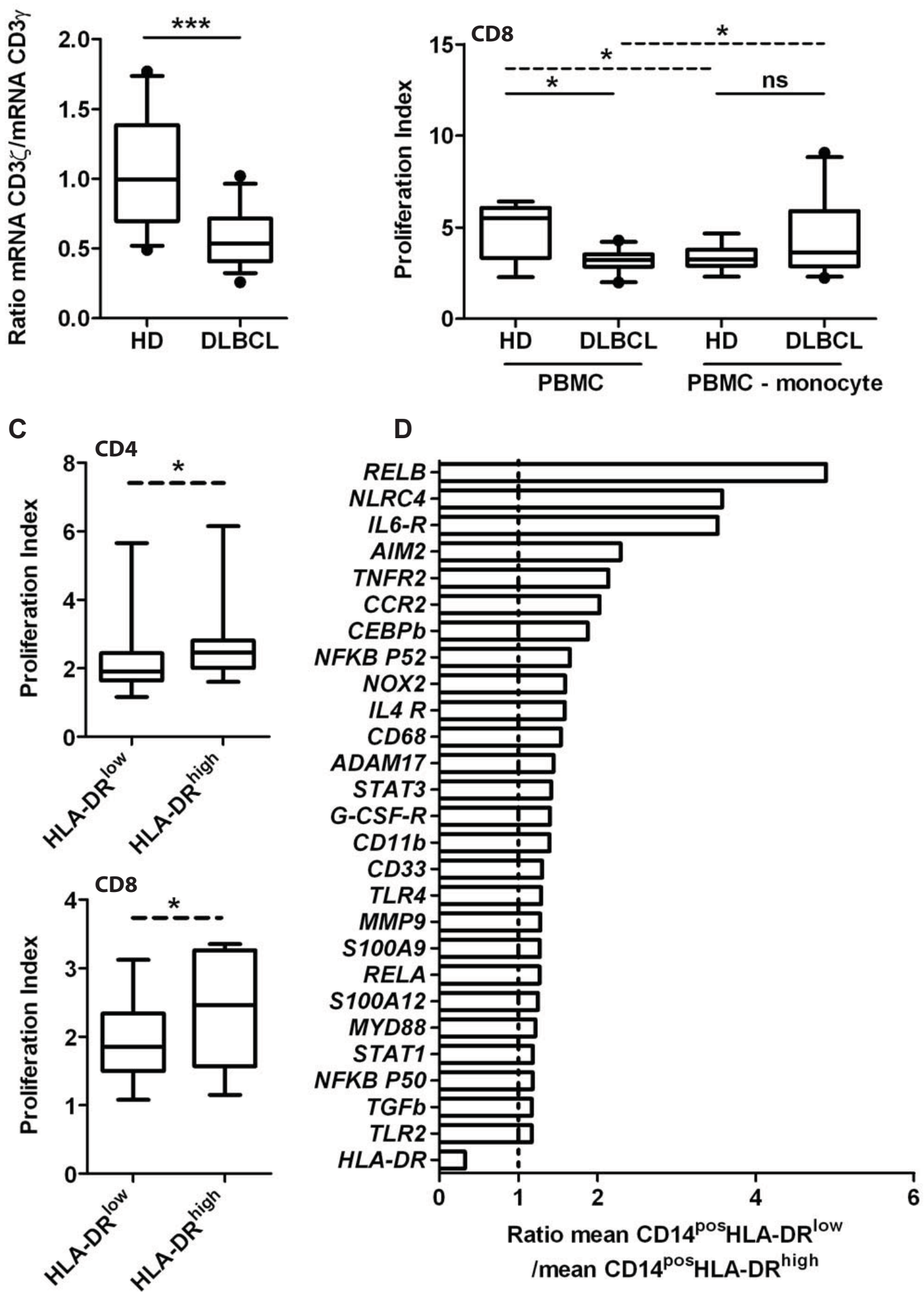
Figure 4

A

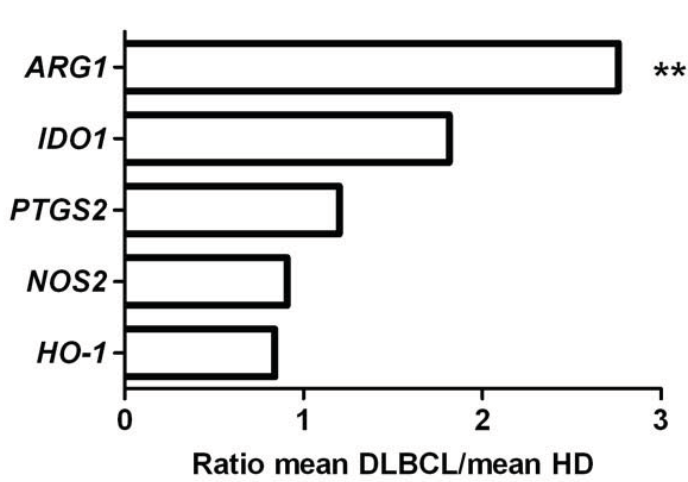

B

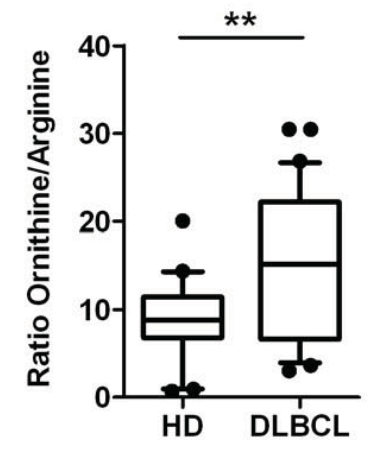

C
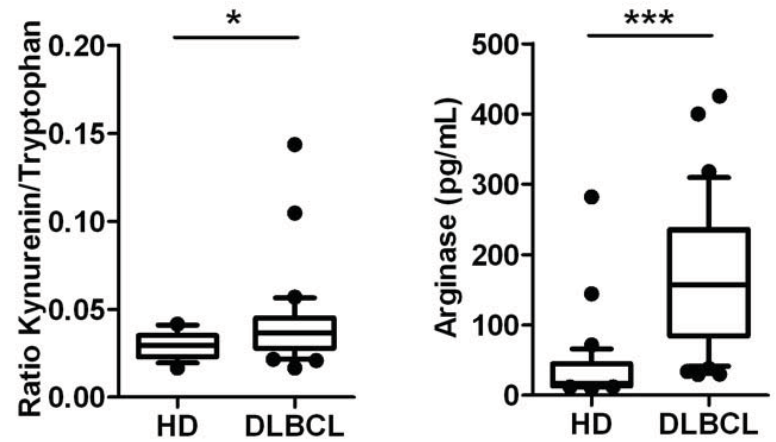

D
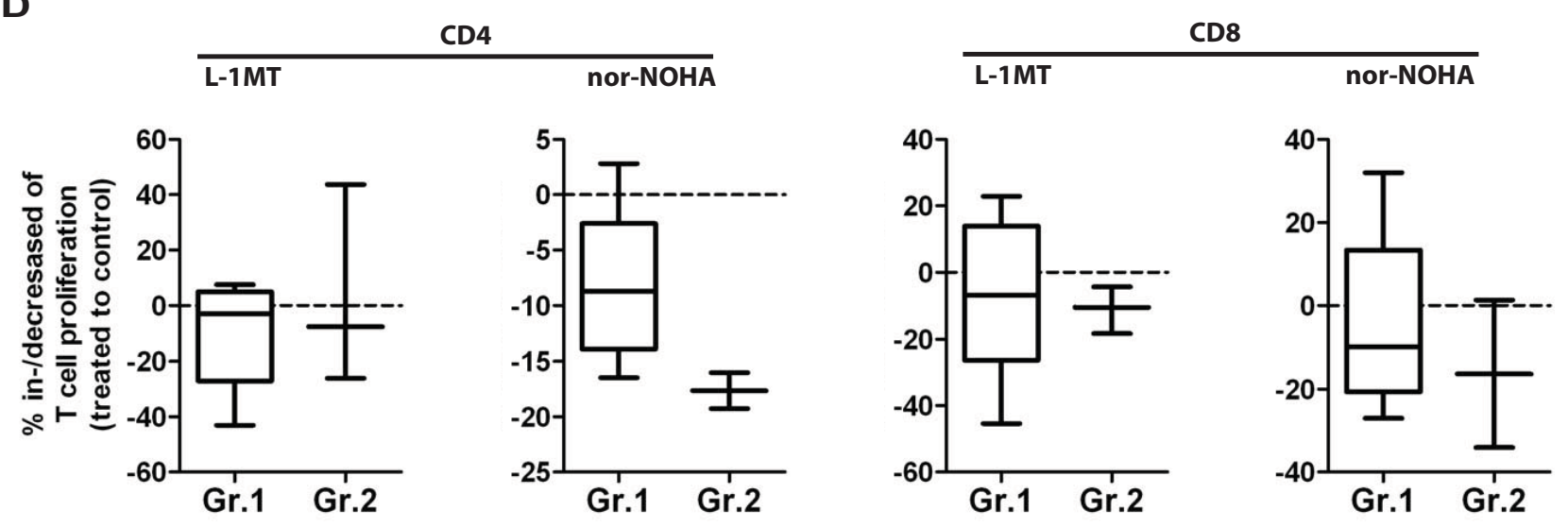

E
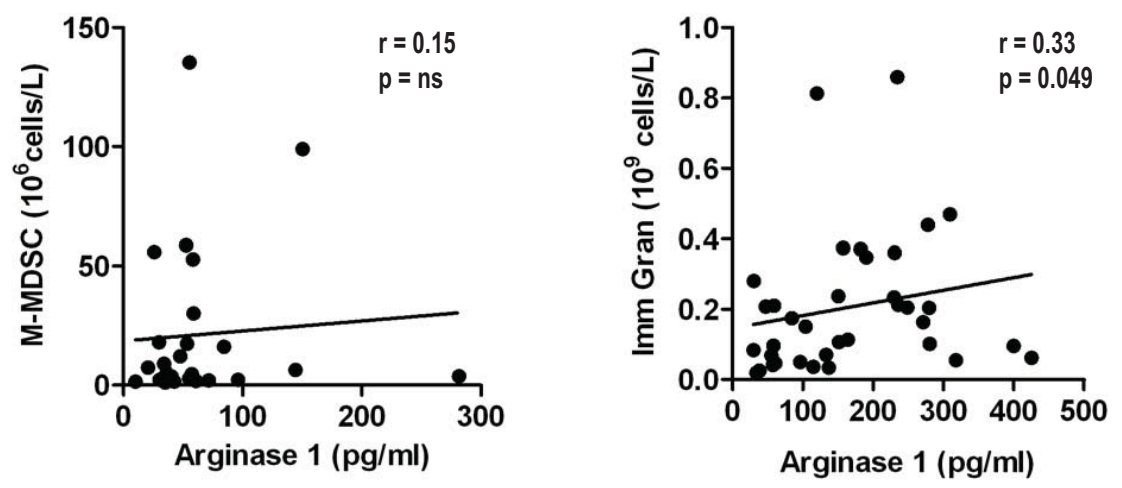
Figure 5

A

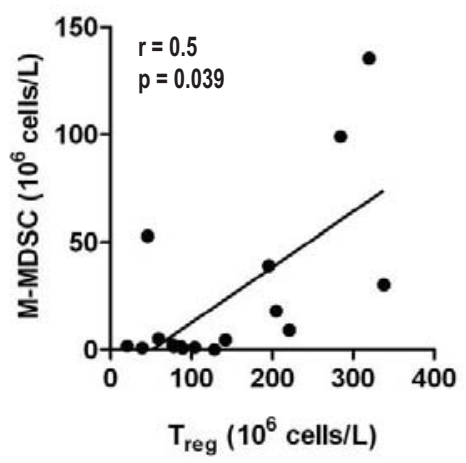

D
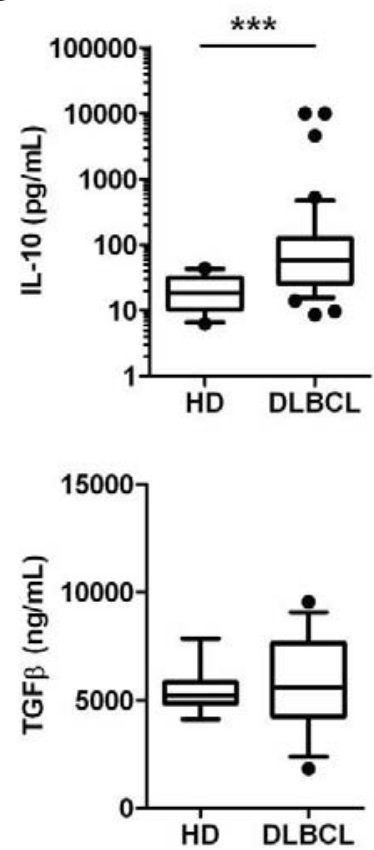

B

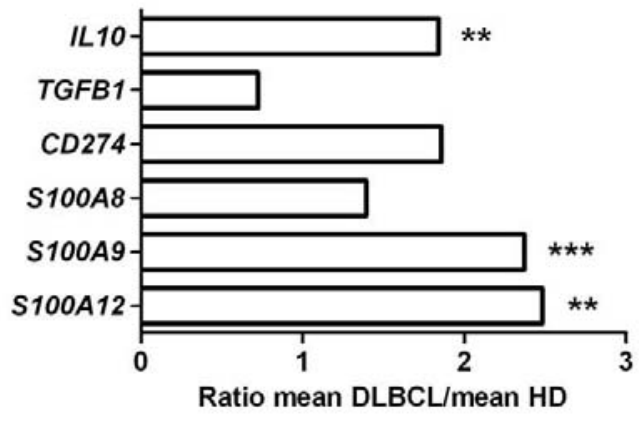

E
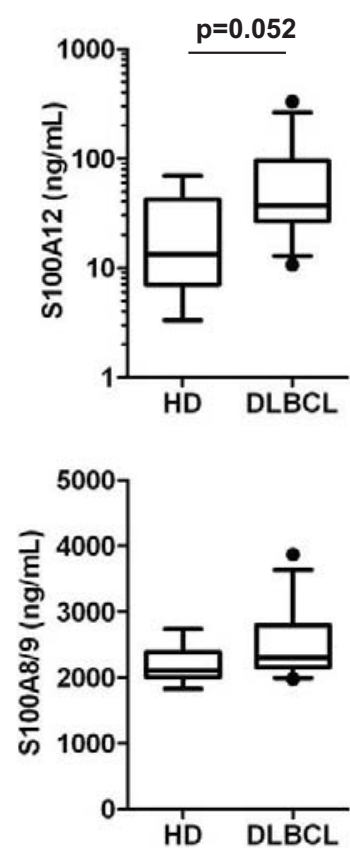

C
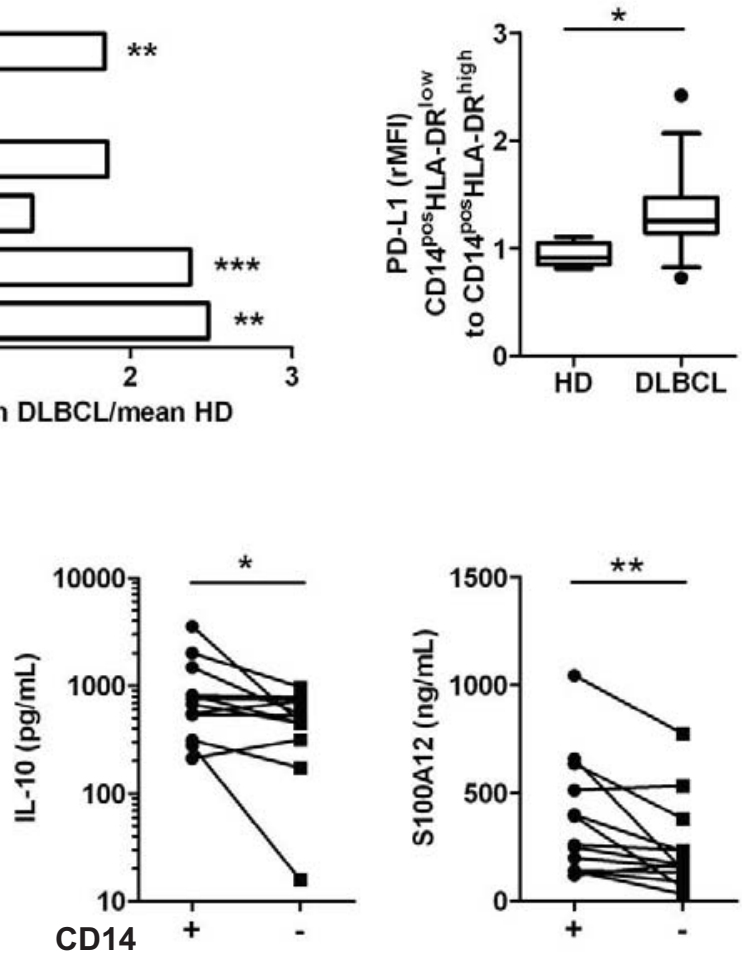
Figure 6

$\alpha-I L-10$

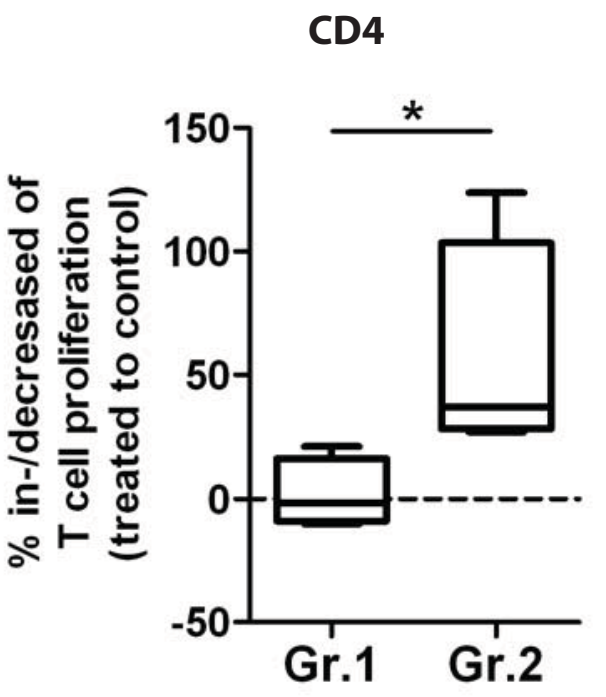

CD8

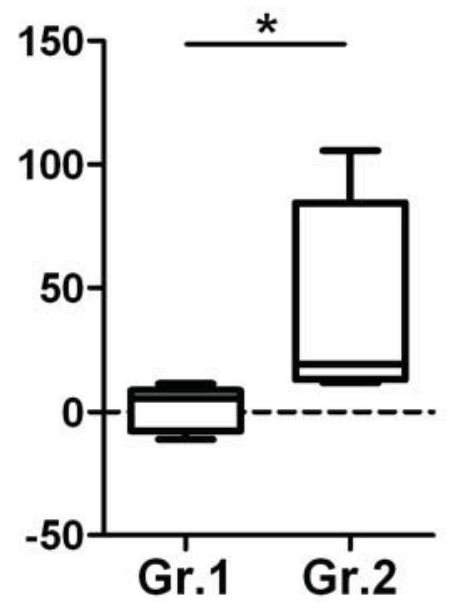

$\alpha-P D-1$
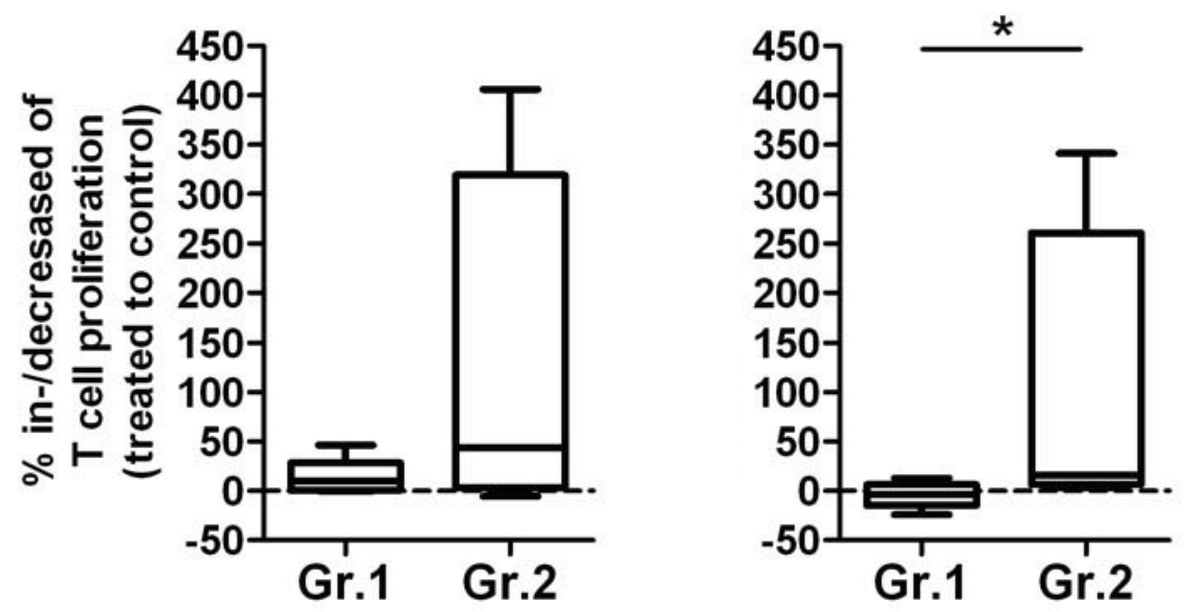

$\alpha-S 100 A 12$
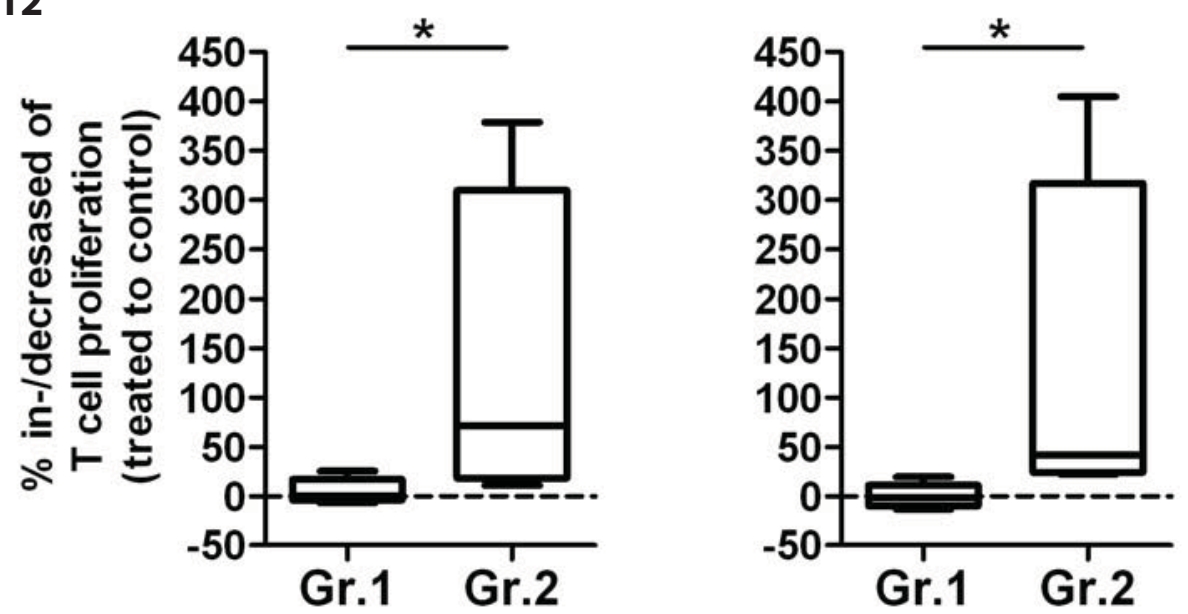